\title{
工资档案的信息化管理工作探讨
}

\author{
陈树栋 ${ }^{1}$ 孙计 $^{2}$ \\ 1 洮南市工资统发管理中心 2 洮南市国库集中支付中心 \\ DOI:10.32629/ej.v2i4.208
}

[摘 要] 进入二十一世纪,信息化技术已拓展应用到生产生活的各个领域,并取得了良好的成效。工资档案是企业人力资源管 理的重要凭证, 而传统档案管理工作流程繁琐,档案资料利用率低。对此,促进信息化技术与工资档案管理的有机整合,可以简化 档案管理流程,提高工作效率,节省时间成本与人力成本,进而维护内部管理工作的有序运转。

[关键词] 工资档案；信息化管理；可行性策略

工资档案是企业经济管理的一个重要方面, 同时也是企 业人事部门对个人管理的重要系证。工资档案的信息化管理 不仅能为企业的改革和发展提供及时、准确的信息依据, 而 且还能促进企业各项工作的顺利开展。本文首先从工资核算 的基本特征与要求进行切入, 在对工资档案信息化管理的优 势进行全面分析的基础上,针对工资档案的信息化管理工作 进行了探讨, 希望能够为更好的推进工资档案管理工作提供 一些参考与帮助。

\section{1 工资核算的基本特征与标准要求}

工资核算是人力资源管理部门的重要工作, 其基本特征 有: (1)工资核算是财务部门与人力资源管理部门的基础业务 业务,对数据信息的完整性、时效性与准确性要求较高; (2) 工资核算涉及面较为宽泛; (3)工资核算业务处理重复性较 强; (4)工资核算信息采集要求较高。

众所周知, 工资是以抽象化的数字为表达载体, 直观化 反馈个人薪资待遇水平的关键信息。为加强企业管理的合理 性, 维护基层员工的合法权益, 应确保工资核算的精确性。

工资档案信息涉及人事档案信息的方方面面。保证基层 员工工资发放的时效性与准确性, 是对工资核算人员的基本 要求。要达到这一要求, 需要依托完善的工资档案信息化管 理系统, 在维护员工基本权益, 维系内部业务正常运转的基 础上, 提升人力资源信息化管理水平。

\section{2 工资档案信息化管理的优势分析}

工资作为个人劳动所得, 充分体现出按劳分配的基本原 则。而工资档案作为反馈个人薪资待遇水平的原始记录, 还 可以从侧面映射出主体市场经济的涨幅与生产能力的增长 速度。以高等教育职业院校为例, 其内部人员架构较为复杂, 既有领导人员、教职人员、行政管理人员，也有大量的后勤 保障人员与临时工作人员, 由于工资结构不同, 其所形成的 工资档案也存在较大差异。工资档案是人力资源档案的重要 组成内容, 是核定教职工职务变化后基本工资调整情况的重 要信息。工资档案与人力资源档案中其它内容的本质性差异 体现在数字化特征方面。在信息技术快速发展的大环境背景 下, 实现工资档案的数字化管理已成为现代化企业建设的重 要标志。
工资档案信息化有利于监管与调整收入分配制度。现行 工资制度的重要特征是人力资源管理由身份管理向岗位管 理过渡, 按照各岗位的性质与员工的资质, 划分薪资待遇等 级。全面推行工资档案信息化管理模式, 这可以保证上级部 门更加及时且准确的掌握收入分配制度, 为人力资源体制的 深化变革提供可靠的参考依据。再者, 工资档案信息化在很 大程度上提升了工作效率与精确性, 节约时间成本与人力资 源成本, 实现资源的优化配置。

另外, 工资档案信息化, 所产生的纸质工资档案格式统 一、美观整洁, 与传统的纸质档案相比保存年限更长, 更利于 保存。除了在信息输入时需要利用档案原件外, 很少再接触 原件, 这就延长了档案的使用寿命。工作人员和利用者还可 以方便地通过计算机和网络在档案室以外的地方查阅利用 工资档案基本信息。

\section{3 工资档案管理工作中存在的主要问题}

3.1工资档案管理模式落后, 综合管理效率偏低

当下, 尽管计算机技术已拓展应用到生产生活的各个方 面, 但是仍有部分企业对档案信息化管理缺乏客观认知, 仍盲 目沿用传统档案管理模式, 这就会导致综合管理效率低下。另 外, 绝大多数基层档案管理人员都是实践经验丰富的老员工, 其计算机操作水平偏低, 仅能掌握简单的办公软件, 无法在短 时间内掌握自动化程度高、运行程序复杂的软件。再者, 由于 部分老员工思想观念陈旧, 适应能力较差, 不习惯于信息化管 理, 这也使得企业工资档案管理效果不够理想。

3.2 工资档案信息化管理水平低

当下, 绝大多数企业已逐步使用计算机系统开展内部管 理工作，且在实践应用中取得了良好的成效。但基于工资档 案管理是一项全面性、系统性的工作, 再加上企业对信息化 的标准要求逐步提高, 所以信息化技术的初级应用无法满足 发展需求。另外, 部分企业的信息库更新不及时, 维护不到位, 导致资源共享受限, 安全保密性不足, 这极大的制约了工资 档案管理信息化管理的发展, 同时也对企业的经营发展造成 了阻碍。

3. 3 缺乏完善的工资档案信息化管理制度

如今, 尽管多数企业充分认知到工资档案信息化管理的 
实际价值, 也顺应时代发展趋势实现了档案信息化管理。但 是由于信息化管理制度不健全, 导致管理工作流于形式, 基 层员工无法实时查询个人电子信息, 也无法核对个人基本情 况, 这就给基层档案管理工作造成了极大的不便。

\section{4 提升工资档案信息化管理水平的可行性策略}

针对企业工资档案管理环节存在的各类问题, 企业应当 客观认知工资档案信息化管理的实际价值, 选择符合发展需 求的资源管理软件, 保证工资档案管理与其它管理内容的兼 容性, 从而建立起健全的信息化管理规章制度, 构建完善的 规范指导体系, 以此完善基层工资档案管理人员专业素养, 促进企业的良好发展。

4. 1客观认知工资档案信息化管理的实际意义

要维系企业工资档案信息化管理工作的有序运转, 首要 前提是企业管理决策层应充分认知工资档案信息化管理的 实际价值, 并将专项管理工作作为企业经营发展的核心内 容。由此, 促使企业加大信息化管理工作的监督力度与执行 力度, 如实反馈基础工作存在的各类问题, 并提出行之有效 的整改措施。

\section{2 选择符合发展需求的资源管理软件}

现阶段, 国内已推出了多款人力资源管理软件, 而财政 部门与人力资源管理部门又各自推出了适用型软件系统。不 同软件系统的内置程序与适用条件各不相同, 且不同软件无 法完全套用。因此, 企业应结合实际情况, 选择适宜的软件系 统, 并充分发挥信息化管理的优势特征。工资档案信息化管 理系统, 可以进一步提升专项管理工作的时效性与准确性。 但需要格外强调的是, 要在应用工资档案管理系统的基础上, 注重工资档案数据的后期维护, 从而为保证工资核算的准确 性提供必要的参考依据。

此外, 单纯注重工资档案的维护远远不够, 还要根据职 工工资的变化情况灵活调整操作系统。企业工资档案管理系 统的升级也是至关重要的。伴随各类工资政策的出台, 企业 需调整工资管理系统, 并在系统升级后, 核对基层职工的工 资信息, 加强系统升级后工资数据的完整性与准确性。

4. 3确保工资档案信息化管理与其它信息化管理的兼容性

企业工资档案信息化管理仅是企业人力资源档案信息 化管理体系的一部分, 为此, 工资档案管理要与职称管理、绩 效考核管理、财务管理与网络管理等协调配合, 从而为整个 管理系统的运转提供必要的支持, 进而提升企业的综合管理
水平, 为基层职工提供优质的服务, 充分发挥信息化管理的 便捷性优势。

4. 4完善基层工资档案信息化管理人员综合素质

工资档案信息化管理的综合效率不仅与管理模式与管 理手段有关, 与基层管理人员的业务水平与职业素养也存在 紧密联系。在推行工资档案信息化管理的过程中, 要求管理 人员具备充足且扎实的管理专业理论知识, 同时, 掌握熟练 的计算机应用能力与信息化管理能力。由此可知, 基层档案 信息化管理人员需秉承优胜劣汰的原则, 不断充实自我, 巩 固基础理论知识, 掌握新理念与新技术, 进而提升专业技能 水平, 强化职业道德素养, 保证信息化管理工作的时效化与 标准化。

4. 5 建立健全信息化管理制度, 构建完善的规范指导体系

信息化管理的规章条例与标准规范是档案信息化管理 工作的指导方针与参考依据。为此, 企业应结合经营发展现 状与档案信息化管理水平, 建立健全信息化管理规章制度, 构建完善的信息化管理标准规范, 确保档案管理工作有法可 依、有章可循、有度可考, 做到基层管理工作的制度化与规 范化。再者, 企业还要设立监督小组, 全方位动态监督整个工 资档案信息化管理流程, 一方面监督专项管理工作流程, 另 一方面监管各项制度的执行效果, 保证信息化管理发挥实际 价值。

\section{5 结束语}

结合以上全文的分析与论述我们可以获知, 在新时期发 展背景下, 企业要秉承与时俱进的基本原则, 将信息化技术 拓展应用到工资档案管理工作中, 与此来实现资源的优化配 置, 提高档案管理效率, 进而维系企业内部管理工作的有序 运转。

\section{[参考文献]}

[1]段燕敏.工资档案的信息化管理工作探讨 [J]. 现代国 企研究,2017,(08):72.

[2]何福贵,吴晓红.工资档案系统设计与实现研究 [J]. 北 京劳动保障职业学院学报,2016,(04):53-55.

[3]段新宇. 论学院工资档案管理的信息化 [J]. 赤峰学院 学报(自然科学版),2015,31(11):176-177.

[4]田瑛.工资档案对个人的作用与影响 [J]. 陕西档 案,2018,(01):38-39. 